\title{
In vitro synergy and antagonism of antifungal agents against yeast-like fungi
}

\author{
B. DUPONT \\ M.D. \\ E. DROUHET
M.D.
}

Institut Pasteur, Service de Mycologie, 75015, Paris

\begin{abstract}
Summary
Some antifungal agents have been tested qualitatively in various associations against species of Candida, Cryptococcus and Torulopsis. The method used was the channel test and the results are confirmed by comparison with the serial dilution test in agar.

The antagonism in vitro with the combination of amphotericin B imidazole suggests that caution must be exercised before prescribing the antifungal drugs in combination for man. The frequent synergy of flucytosine with econazole is, however, encouraging because of the low toxicity of the 2 drugs. Under the limited conditions described, the combination of flucytosine and amphotericin B was not found synergistic but additive on the strains of $C$. albicans used in this study. This combination was found synergistic for a strain of $C$. parapsilosis and is useful for avoiding resistance to flucytosine.
\end{abstract}

\section{Introduction}

The usual doses of antifungal agents used in human therapy are fungistatic and not fungicidal. Numerous fungi have a high mutation rate in the presence of flucytosine when this drug is given alone. The chromosomal mutation involves development of secondary resistant strains which do not respond to flucytosine. By using 2 antifungal agents, failures in therapy are less likely to occur. Better results are produced and the emergence of mutants resistant to one of the drugs is suppressed. However, an association of 2 antifungal agents is not always synergistic and the result of their action is sometimes only additive or even antagonistic. It is consequently necessary to test in vitro the effect of the association of 2 antifungal agents on the strain responsible for the mycosis (Ansehn, 1977; Dupont and Drouhet, 1978; Medoff, Comfort and Kobayashi, 1971; Polak, 1974; Shadomy, Wagner and Davis, 1975).

The usual technique for studying synergy or antagonism is by making serial dilutions to determine the minimal inhibitory concentration (MIC) for each antifungal agent and then to evaluate the antifungal agents associated by pairs according to every combination of various concentrations. How- ever, with 3 antifungal agents, such a study is very long and cannot be used routinely for clinical application.

A rapid and simple technique was proposed to determine whether combination of antifungal agents is synergistic or not (Dupont and Drouhet, 1978). This method is derived from a technique using paper strips impregnated with antibiotics employed in bacteriology for the study of antibacterial combinations (Chabbert, 1973).

\section{Materials and methods}

Twenty-six strains of Candida albicans, 22 strains of Cryptococcus neoformans all of human origin and one strain of Candida parapsilosis, agent of a fungal endocarditis (Dupont, Drouhet and Lapresle, 1977) were studied. The inoculum for the tests contained $10^{6}$ yeast cells $/ \mathrm{ml}$ cultured by shaking for $18 \mathrm{hr}$ in Sabouraud glucose liquid medium.

The media used were: yeast morphology agar (YMA, Difco), a chemically defined medium which permits the testing of flucytosine, amphotericin B and imidazole derivatives, and a complex medium consisting of casitone Difco $19 \mathrm{~g}$, yeast extract $5 \mathrm{~g}$, sodium nitrate $10 \mathrm{~g}$, disodium phosphate one $\mathrm{g}$, charcoal purified glucose $10 \mathrm{~g}$, agar $20 \mathrm{~g}$, water $1000 \mathrm{ml}$. This medium ( $\mathrm{pH} \mathrm{6.6)}$ is effective for testing amphotericin B and econazole but not for flucytosine.

The media were poured into Petri dishes $(15 \mathrm{ml}$ for a 9-cm diameter dish) and dried for $30 \mathrm{~min}$ in the incubator. Four channels ( $40 \mathrm{~mm}$ long, $2 \mathrm{~mm}$ wide) were cut in the agar. The channels were at right angles to each other but not connected. The concentrations of the antifungal agents in the channels were as follows: $10 \mathrm{mg} / \mathrm{l}$ for amphotericin $B$ and econazole with casitone medium; $5 \mathrm{mg} / \mathrm{l}$ for flucytosine; $20 \mathrm{mg} / \mathrm{l}$ for amphotericin B; $50 \mathrm{mg} / \mathrm{l}$ for econazole on YMA. The Petri dishes were then incubated for $24 \mathrm{hr}$ at $30^{\circ} \mathrm{C}$ for Candida strains, and $48 \mathrm{hr}$ for $\mathrm{Cr}$. neoformans strains. The reading of inhibition areas states the evaluation of the sensitivity or resistance strain to each antibiotic. In particular, it is mainly the growth around the angle of the 2 channels which is important. If the 2 

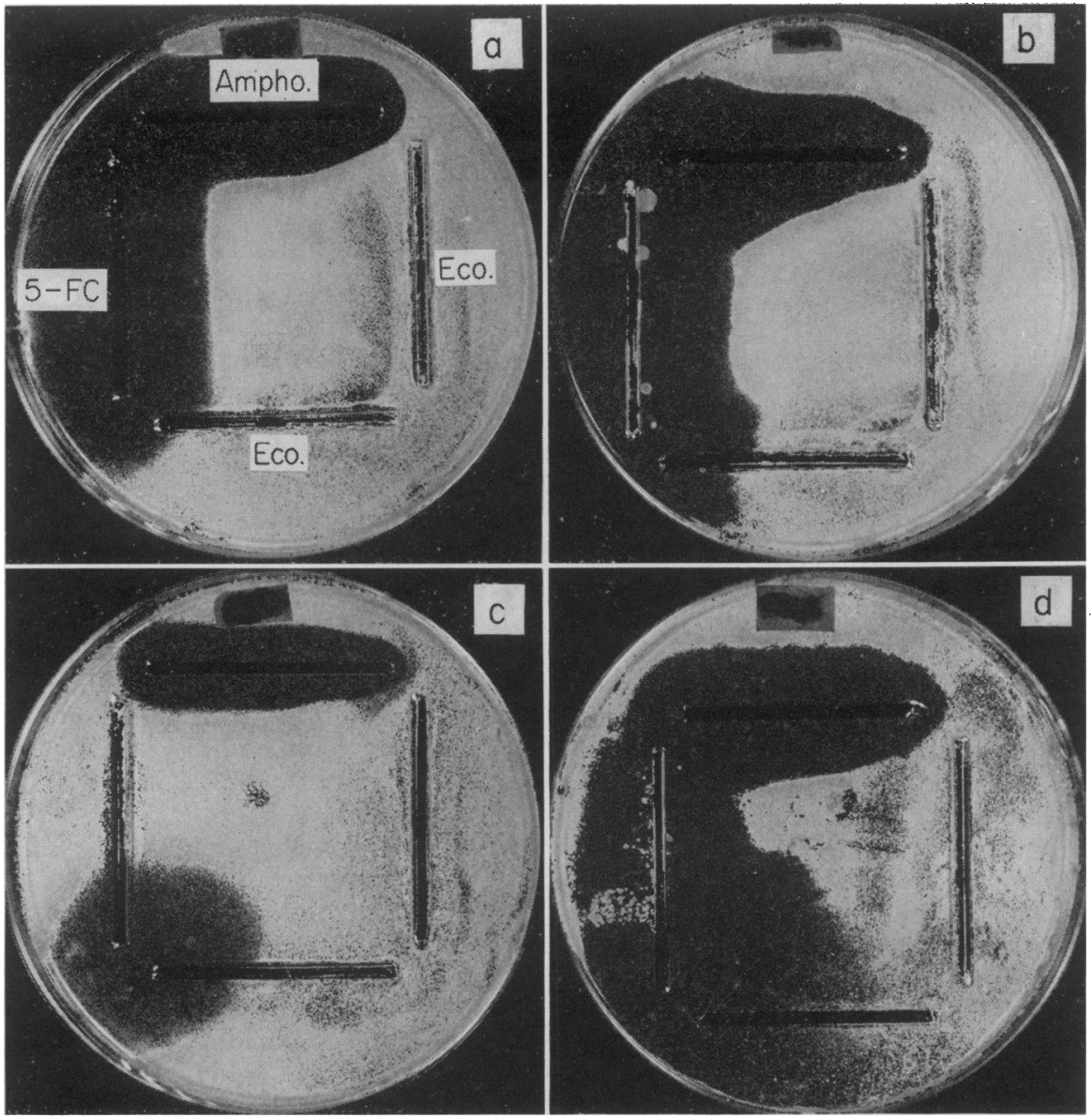

Fig. 1 (a-d). Channel test - yeast morphology agar (YMA) medium. Ampho. = Amphotericin B; Eco. = Econazole; 5-FC. = Flucytosine.

No synergy between flucytosine and econazole: (a).

Synergy between flucytosine and econazole: (b, c and d). Antagonism between amphotericin B and econazole: $(a-d)$.

Possible synergy between amphotericin B and flucytosine: (b).

inhibition areas intersect at right angles, the effect is indifferent, if the inhibition areas draw a hyperbole, the combination demonstrates an additive effect. An angle with a notch shows a synergistic effect. A reverse image shows an antagonism which can be reciprocal or predominant for the one or the other antifungal agent.

The results from the channel technique were compared with results from the conventional technique of determination of the MIC, i.e. by serially diluting the antifungal agents alone and in combination in the agar media described, and poured into Petri dishes. For this comparison, inocula of 4 strains of C. albicans (Nos 4, 5, 7, 21, obtained from cultures shaken in Sabouraud liquid medium for $18 \mathrm{hr}$ at $37^{\circ} \mathrm{C}$ ) were inoculated to agar medium by a modified Steers apparatus; this inoculum corresponds to 100 distinct colonies. The MIC and the concentration of antibiotic which inhibits $50 \%$ of the inoculum $\left(\mathrm{IC}_{50}\right)$ were determined by reading the growth after incubation for $18 \mathrm{hr}$ at $37^{\circ} \mathrm{C}$.

The bacteriological criteria for synergy and antagonism adopted were as follows: there was synergism when growth inhibition was obtained with one-quarter the MIC $\left(\frac{\mathrm{MIC}}{4}\right)$ of one antibiotic combined with the equivalent concentration of the other. 


\section{Results}

Strains of $C$. albicans responded to drug combinations as follows: antagonism is always observed with amphotericin B plus econazole; antagonism is observed with both casitone medium and YMA medium, but it is more readily observed in the former. The best time for observation of this is after several days at room temperature. A secondary growth can be observed in the inhibition area of amphotericin B, which is situated in the diffusion zone of econazole. The antagonism is also constant between amphotericin B and miconazole for the 26 strains tested (Table 3).

TABLE 1. Minimal inhibitory concentration (MIC) and antagonism between amphotericin B (Ampho.) and econazole (Eco.) on 2 strains of Candida albicans

\begin{tabular}{ccccc}
\hline & \multicolumn{2}{c}{ MIC mg/l } & & \\
\cline { 2 - 4 } Strain No. & Ampho. & Eco. & Ampho. + Eco. & FIC* \\
\hline 4 & 0.02 & 0.04 & $\begin{array}{c}0.02+0.04 \\
\text { No inhibition }\end{array}$ & $>2.0$ \\
5 & 0.08 & 0.04 & $\begin{array}{c}0.08+0.02 \\
\text { No inhibition }\end{array}$ & $>1.5$ \\
\hline
\end{tabular}

* FIC, fractional inhibition concentration.

Using the conventional technique of serial dilution of antifungal agents, the authors demonstrated antagonism in all 4 strains of $C$. albicans. For strain no. 4, the MIC of amphotericin B is $0.02 \mathrm{mg} / \mathrm{l}$ and of econazole it is $0.04 \mathrm{mg} / \mathrm{l}$. If the 2 antibiotics had an additive effect, the inhibition of growth would be obtained with $0.01 \mathrm{mg} / 1$ of amphotericin B and $0.02 \mathrm{mg} / \mathrm{l}$ of econazole. However, there is no inhibition with $0.02 \mathrm{mg} / \mathrm{l}$ amphotericin $B+0.04 \mathrm{mg} / \mathrm{l}$ econazole (Table 1 ).

The antagonistic effect is, nevertheless, limited. Inhibition can be seen if the concentration of amphotericin B or econazole is 2-3 times $>$ the
MIC. The sum of the fractional inhibitory concentration (FIC) for strain no. 4 is $>2$ (Table 1). Similar results were observed with strain no. 5 (Table 1).

For the other 2 strains ( 7 and 21 ) a more accurate method than the MIC was necessary to observe antagonism: the MIC is sometimes difficult to determine, particularly in the case of econazole, when there is a growth of very small colonies, even in high concentrations; thus, the determination of the $\mathrm{IC}_{50}$ seems more reliable and reproducible. On the other hand, MIC determination by 2 -fold serial dilutions can be misleading. For example, if the MIC is quoted as $\mathbf{0 . 0 8}$, this means that the culture grows at 0.04 but not at 0.08 , the real MIC being between these 2 values and could, in fact, be nearer to 0.04 than 0.08 although the latter is the quoted MIC.

TABLE 2. Median inhibitory concentration $\left(\mathrm{IC}_{50}\right)$ and antagonism between amphotericin $\mathbf{B}$ (Ampho.) and econazole (Eco.) on 2 strains of Candida albicans

\begin{tabular}{ccccc}
\hline & \multicolumn{2}{c}{$\mathrm{IC}_{50}$} & & \\
\cline { 2 - 3 } Strain No. & $\begin{array}{c}\text { Ampho. } \\
(\mathrm{mg} / \mathrm{l})\end{array}$ & $\begin{array}{c}\text { Eco. } \\
(\mathrm{mg} / \mathrm{l})\end{array}$ & Ampho. + Eco. & FIC* \\
0.04 & 0.08 & $\begin{array}{c}0.04+0.08 \\
\text { No inhibition }\end{array}$ & $>2.0$ \\
21 & 0.04 & 0.02 & $\begin{array}{c}0.04+0.04 \\
\text { No inhibition }\end{array}$ & $>3.0$ \\
\hline
\end{tabular}

* FIC, fractional inhibition concentration.

Table 2 shows the antagonism between amphotericin $\mathrm{B}$ and econazole stated in $\mathrm{IC}_{50}$ and the sum of FIC shows clearly an antagonistic effect.

The combination of flucytosine and econazole, contrary to the previous one, shows a synergistic effect. This was obtained on 22 of $26 C$. albicans strains. For 5 strains (Table 3) the synergism was particularly intense; this can be controlled by calculation of MIC and of MIC fractions. The lowest synergy gave an inhibition of the growth with

TABLE 3. Number of strains for which the combination of antifungal agents (amphotericin B, flucytosine, econazole, miconazole) has a synergistic, antagonistic, additive, or no effect

\begin{tabular}{|c|c|c|c|c|}
\hline \multirow{2}{*}{$\begin{array}{l}\text { Antifungal agents } \\
\text { combination }\end{array}$} & \multirow[b]{2}{*}{ Strain of fungus } & \multicolumn{3}{|c|}{ Activity } \\
\hline & & Synergy & Antagonism & Additive or none \\
\hline $\begin{array}{l}\text { Amphotericin B } \\
\stackrel{+}{+} \\
\text { flucytosine }\end{array}$ & $\begin{array}{l}\text { Candida albicans } \\
\text { C. parapsilosis } \\
\text { Cryptococcus neoformans }\end{array}$ & $\begin{array}{l}0 \\
1 \\
0\end{array}$ & $\begin{array}{l}0 \\
0 \\
0\end{array}$ & $\begin{array}{r}26 \\
0 \\
22\end{array}$ \\
\hline $\begin{array}{l}\text { Amphotericin B } \\
\quad+ \\
\text { econazole or miconazole }\end{array}$ & $\begin{array}{l}\text { C. albicans } \\
\text { Cr. neoformans }\end{array}$ & $\begin{array}{l}0 \\
0\end{array}$ & $\begin{array}{l}26 \\
22\end{array}$ & $\begin{array}{l}0 \\
0\end{array}$ \\
\hline $\begin{array}{l}\text { Flucytosine } \\
+ \\
\text { econazole or miconazole }\end{array}$ & $\begin{array}{l}\text { C. albicans } \\
\text { Cr. neoformans }\end{array}$ & $\begin{array}{r}22 \\
6\end{array}$ & $\begin{array}{l}0 \\
1(?)\end{array}$ & $\begin{array}{r}4 \\
15\end{array}$ \\
\hline
\end{tabular}


$\frac{\text { MIC }}{8}$ of flucytosine associated with the equivalent of econazole. The greatest synergy produced was obtained with the MIC of flucytosine plus the MIC $64 \quad \frac{}{32}$

of econazole. For the 4 strains considered to be insensitive to a synergistic effect, growth could still take place with a combination of antibiotics equiva-

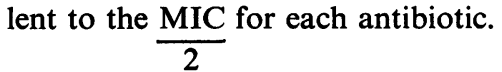

Synergism between flucytosine and econazole was observed with 2 flucytosine-resistant strains.

The combination of flucytosine and amphotericin B shows only an additive or indifferent effect. However, it was possible to show synergy with this combination against a strain of $C$. parapsilosis. The strain was obtained from a woman with endocarditis following a Starr-Edwards prosthesis (Dupont et al., 1977). Treatment with this combination of antifungal drugs was successful and further surgery was unnecessary.

With $C r$. neoformans, the results are similar to those for $C$. albicans and, for all the 22 strains tested, the authors have not observed synergism between amphotericin B and flucytosine. However, antagonism is constantly observed between amphotericin B and econazole or miconazole (Table 3).

The combination of flucytosine and econazole is less often and less intensively synergistic for Cryptococcus than for Candida.

A strong synergistic effect was observed for 6 of 22 strains; nevertheless, 17 of the 22 were resistant to flucytosine and synergism was not observed in these 17 strains.

\section{Discussion}

The Candida and Cryptococcus genera show a similar antagonism to the combination of amphotericin $\mathrm{B}$ and imidazole. The in vitro results are dependent on various conditions: medium, inoculum and antifungal concentration. Such results do not necessarily permit a direct extrapolation to in vivo conditions. However, Schacter, Owellen and Buck (1976) found this antagonism in man. For Ansehn (1977), an in vitro study suggested a synergy of the amphotericin B econazole association for C. albicans. The authors' preliminary studies on Torulopsis sp. demonstrate an antagonism of this genus to the combination of amphotericin B and imidazole, so that it is possible that this may also apply to all 3 genera.

The combination of flucytosine and imidazole is often synergistic, particularly against $C$. albicans. The synergy may even exist with strains resistant to flucytosine as already shown for the combination of flucytosine and amphotericin B. In contrast to other workers, the authors were not able to find a synergy between flucytosine and amphotericin $B$ for $C$. albicans. This might be due to the synthetic medium as well as to the differences mentioned above (material and methods). Nevertheless, this combination is very useful in practice as amphotericin B suppresses the resistant mutants.

\section{References}

ANSEHN, S. (1977) In vitro synergistic action of antimycotics and antibiotics on Candida albicans. Current Therapeutic Research, 22, 92.

Chabbert, Y.A. (1973) Antibiotiques en bactériologie médicale. In: Techniques en Bactériologie III (Ed. by Daguet, G.L. \& Chabbert, Y.A.) vol. III. Flammarion Médecine, Sciences, Paris.

Dupont, B. \& Drouhet, E. (1977) Méthode rapide de détermination de la synergie antifongique. Bulletin de la Société Française de Mycologie Médicale, 6, 291.

Dupont, B. \& Drouhet, E. (1978) Antagonisme in vitro de l'association amphotéricine B-éconazole sur Candida albicans. Bulletin de la Société Française de Mycologie Médicale, 7, 85.

Dupont, B., Drouhet, E. \& Lapresle, C. (1977) Première guérison médicale d'une endocardite à Candida sur prothèse valvulaire. Annales de Médecine Interne, 128, 699.

Medoff, G., Comfort, M. \& Kobayashi, G.S. (1971) Synergistic action of amphotericin B and 5-fluorocytosine against yeast-like organisms. Proceedings of the Society for Experimental Biology and Medicine, 138, 571.

PolaK, A.M. (1974) Détermination de la synergie entre la 5fluorocytosine et l'amphotéricine $B$ au moyen de différents modèles in vitro et in vivo. Bulletin de la Société Française de Mycologie Médicale, 3, 175.

Schacter, L.P., OWellen, R.J., Rathbun, H.K. \& Buchanan, B. (1976) Antagonism between miconazole and amphotericin B. Lancet, ii, 318.

Shadomy, S., Wagner, G. \& Davis, B.A. (1975) In vitro studies with combinations of 5-fluorocytosine and amphotericin B. Antimicrobial Agents and Chemotherapy, 8, 117. 